DOI: $10.5277 /$ epe 160302

\title{
USE OF NANOFILTRATION MEMBRANES TO CONCENTRATE AND RECOVER LEACHED ALUMINUM FROM ACIDIFIED WATER TREATMENT SLUDGE
}

\begin{abstract}
The recovery of aluminum from water purification sludge is usually performed by making the solution acidic or basic. However, for economic reasons and reasons of safety, excessive doses of acid or base should not be utilized. Accordingly, the aluminum concentration in the leached solution is typically limited, thus the recovered aluminum cannot be directly reused as a coagulant. A nanofiltration (NF) membrane can be used in the acidic solution to concentrate high-valence metal ions. Therefore, in this work, $\mathrm{H}_{2} \mathrm{SO}_{4}$ was utilized to leach $\mathrm{Al}^{3+}$ ions from water purification sludge. Then, the $\mathrm{Al}^{3+}$ ion solution was concentrated using a low-price NF membrane. The effect of natural organic matter on the $\mathrm{Al}^{3+}$ ion concentrating efficiency in the filtration process has been elucidated. Experimental results reveal that $\mathrm{Al}^{3+}$ ions were effectively prevented from passing through the $\mathrm{NF}$ membrane, enabling a highly concentrated aluminum solution to be obtained. However, the presence of organic compounds may reduce the efficiency of the concentration of $\mathrm{Al}^{3+}$ ions in the solution.
\end{abstract}

\section{INTRODUCTION}

In the water treatment process, aluminum sulfate or polyaluminum chloride $(\mathrm{PACl})$ is generally used as a coagulant to react with particles to form precipitated sludge. The coagulation process causes a large amount of aluminum hydroxide $\left(\mathrm{Al}(\mathrm{OH})_{3}\right)$ which is present in the sludge along with organic matter, silicon salts, metal ions and other metal hydroxides. Therefore, many scholars have studied the recovery of aluminum from water treatment sludge. The main methods of recovery fall into four categories such as acidification, basification, membrane separation, and ion exchange [1].

Aluminum can be recovered from $\mathrm{Al}(\mathrm{OH})_{3}$ sludge because aluminum hydroxide can dissolve in both acidic and basic solutions. In the method of acidic $\mathrm{pH}$ adjustment, inorganic

${ }^{1}$ Department of Safety, Health and Environmental Engineering, National United University, Miaoli, Taiwan 360, corresponding author W.P. Cheng, e-mail: cwp@ nuu.edu.tw

${ }^{2}$ Institute of Natural Resource Management, National Taipei University, New Taipei City, Taiwan 237. 
acid is added to the alum sludge to leach $\mathrm{Al}^{3+}$ ions [2]. Panswad and Camnan [3] found that when sulfuric acid was used in the recovery of aluminum at $\mathrm{pH} 1-3$, the aluminum recovery rate reached $70-90 \%$. A lower $\mathrm{pH}$ enables more aluminum to be dissolved and recovered from the sludge, but at increased cost and hazard. Additionally, acidified sludge is hazardous. In the basic $\mathrm{pH}$ adjustment method of aluminum recovery, sodium hydroxide or calcium hydroxide is typically utilized to leach $\mathrm{Al}(\mathrm{OH})_{4}^{-}$ions. When $\mathrm{pH}$ is adjusted to $11.2-11.8$, a relatively high aluminum recovery rate is obtained [4]. However, in the basification process, the organic matter in the alum sludge easily dissolves in a strongly alkaline solution, inhibiting the recovery of the aluminum. Therefore, most related recent research involves acidic $\mathrm{pH}$ adjustment. Recovery of highly concentrated aluminum ions depends on a large amount of both sludge and inorganic acid. Separating solid from liquid in such mixed sludge is very costly [5]. Therefore, for economic reasons, only aluminum ions at concentrations of several hundreds or thousands of $\mathrm{mg} / \mathrm{dm}^{3}$ can be dissolved using the acidification method. This approach is still far from being commercially viable.

The ion exchange method does not recover a high concentration of aluminum ions [6]. Therefore, some membrane filtration methods have recently been used to recover aluminum. Li and Sengupta [7] used composite ion exchange membranes to recover $\mathrm{Al}^{3+}$ ions. First, a composite membrane is placed in contact with the acidified sludge for selectively attracted aluminum ions from the acidified sludge. Second, the chelating exchanger of the composite membrane is regenerated by the desorption of the metal ions in a stirred regeneration tank that contains acid. However, this method is somewhat limited in the degree to which it can concentrate $\mathrm{Al}^{3+}$ ions. Additionally, the composite ion exchange membrane has not yet been commercialized and is not extensively used. Prakash and Sengupta [8] used an ion exchange membrane method based on the Donnan effect to recover aluminum from water treatment sludge. Although they achieved extremely high recovery rates, in their experiment, a high concentration of acid solution was used as the feed solution to increase the aluminum ion recovery rate. Moreover, the membrane they used was extremely expensive.

A high flux of a solution can pass through a nanofiltration (NF) membrane at a relatively low pressure; it can concentrate the target substance in a short period keeping down operating costs $[9,10]$. Donnan exclusion causes the NF membrane effectively to catch high-valence metal ions [11]. Based on previous research, a NF membrane can be used under extremely acidic conditions [12]. Therefore, NF membranes have recently been used to treat wastewater that contains either organic or inorganic matter, including for example, acidified wastewater from the metal industry [13-15]. NF membranes have also been utilized to concentrate or recover metal ions from wastewater [16] and to recover phosphorus from sewage sludge [17]. However, only a few researchers applied NF membranes to recover the alum-sludge in the field [18]. Therefore, in this work, a commercialized, low-priced NF membrane was used to concentrate aluminum ions 
from an acidified sludge solution. Filtration was used to concentrate the aluminum for reuse.

In a membrane process, liquid is passed under elevated pressure through a NF membrane [19]. In membrane filtration, the relationships among membrane flux, rejection rate and osmotic pressure are expressed as the following equations [20]:

$$
J_{v} \equiv \frac{1}{A} \frac{d V}{d t}
$$

where $J_{v}$ represents the membrane flux $\left(\mathrm{dm}^{3} /\left(\mathrm{m}^{2} \cdot \mathrm{h}\right)\right), A$ is the area of the membrane that is used for filtration $\left(\mathrm{m}^{2}\right), V$ is the permeated liquid volume $\left(\mathrm{dm}^{3}\right)$, and $t$ is the filtration time (h).

$$
R_{i}=100\left(1-\frac{C_{P}}{C_{B}}\right)
$$

where $R_{i}$ is the rejection rate, $C_{P}$ is the concentration of the permeate, and $C_{B}$ is the bulk concentration.

$$
\pi=C_{M} R T
$$

where $\pi$ is the osmotic pressure $(\mathrm{kPa}), C_{M}$ is the sum of the aluminum concentration (mole/ $/ \mathrm{dm}^{3}$, which is calculated as aluminum concentration $\left(\mathrm{mg} / \mathrm{dm}^{3}\right) / 27000(\mathrm{mg} / \mathrm{mole})$ ) and the total organic carbon concentration $\left(\mathrm{mole} / \mathrm{dm}^{3}\right.$, which is calculated as the total organic carbon concentration $\left.\left(\mathrm{mg} / \mathrm{dm}^{3}\right) / 12000(\mathrm{mg} / \mathrm{mole})\right), R$ is the ideal gas constant, and $T$ is the absolute temperature $(\mathrm{K})$.

In this work, aluminum sludge was added to sulfuric acid solutions of various concentrations to dissolve the aluminum ions. After the sludge solid had settled, the supernatants were extracted to be concentrated using the NF membrane. The parameters of membrane flux, recovery concentration and osmotic pressure during filtration using the $\mathrm{NF}$ membrane at various pressures were discussed. In the acidification process, the organic matter inside the sludge was also dissolved. Therefore, the effect of the organic matter on the recovery of aluminum has been discussed.

\section{EXPERIMENTAL}

Preparation of water treatment sludge. The sludge sample was taken from the sludge-drying bed of the water treatment plant of Ming-Der Dam, Miao-Li County, Taiwan. The sludge sample was dried at $105^{\circ} \mathrm{C}$, ground, and well mixed. 
Membrane material and experimental equipment. All filtration experiments were carried out in a tangential cross-flow mode with recirculation and continuous removal of the permeate stream. The retained liquid (bulk) in the filtration process was continuously circulated into the feed tank and the permeate liquid was collected in a $5 \mathrm{dm}^{3}(\mathrm{PE})$ bottle.

The NF membrane was an HL1812T (GE, USA). The membrane surface constituted a three-dimensional cross-linked aromatic polyamide. The filtration area was $0.5 \mathrm{~m}^{2}$. The tolerable pressure for membrane filtration was in the range 0.39-1.57 MPa. The molecular weight cut-offs were 150 and $300 \mathrm{Da}$. The ultrafiltration (UF) membrane was an FCS-DF50-2012 (Rum-Tech. Taiwan). The material of the UF membrane was polyvinylidenefluoride (PVDF). The filtration area was $0.5 \mathrm{~m}^{2}$. The allowed pressures for membrane filtration were in the range $0.30-0.68 \mathrm{MPa}$. The molecular weight cutoff was $50000 \mathrm{Da}$. Before a new membrane could be used, it was soaked in clean water for $24 \mathrm{~h}$, before being flushed for $2 \mathrm{~h}$ with pressured water.

Experimental procedures. The first series of experiments were performed to determine the aluminum rejection rates of UF and NF membranes. An aluminum sulfate solution of the concentration of $1000 \mathrm{mg} \mathrm{Al} l^{3+} / \mathrm{dm}^{3}$ was prepared. In aluminum rejection tests, this solution was filtered using filtration systems with UF and NF membranes. The filtration pressure was set to $0.67 \mathrm{MPa}$. Then, the rejection rates in the UF and NF membrane tests were compared.

The other series of experiments elucidated the relationships between the aluminum concentration in the feed and that in the concentrated solution. To prepare the feed solutions, aluminum sulfate solutions that contained 250,1000 and $2000 \mathrm{mg} \mathrm{Al} l^{3+} / \mathrm{dm}^{3}$ were prepared and their volumes were 20,5 and $2.6 \mathrm{dm}^{3}$, respectively. When the NF membrane was used, the filtration pressure was set to $0.67 \mathrm{MPa}$. The aluminum concentrations of the feed were compared with those after filtration.

The operating $\mathrm{pH}$ for the NF membrane is suggested to be between 2 and 12, not lower than 1.5 and not higher than 13 . To prevent damage to the membrane due to extremely low $\mathrm{pH}$, the effect of the concentration of sulfuric acid on the $\mathrm{Al}^{3+}$ leaching was examined using a set of samples that had been prepared by adding $1000 \mathrm{~cm}^{3}$ of 0.05 , $0.15,0.25,0.35$ and $0.5 \mathrm{M}$ sulfuric acid to $60 \mathrm{~g}$ sludge samples. After $3 \mathrm{~h}$ of mixing, the samples were collected for analysis to determine $\mathrm{pH}$ and the amount of soluble $\mathrm{Al}^{3+}$. In these experiments, a suitable condition was applied to conduct the NF membrane test.

The last series of experiments was performed to determine the effects of sludge acidification, organic matter and filtration pressure on aluminum recovery in the NF filtration tests. To examine the effect of acidification, the sludge that was used in the tests was obtained from the water treatment plant of the Min-der reservoir. Three $300 \mathrm{~g}$ samples of sludge were separately added into $5 \mathrm{dm}^{3}$ of $0.035,0.05$ and $0.15 \mathrm{M}$ sulfuric acid solutions, which were then stirred for $3 \mathrm{~h}$. After settling, $4 \mathrm{dm}^{3}$ of the supernatant of each sludge solution was separately filtered through the NF membrane under the 
pressure of 0.67 MPa. To study the effect of organic matter on aluminum recovery, the above procedure was repeated to obtain $4 \mathrm{dm}^{3}$ of supernatant from a $0.05 \mathrm{M}$ sulfuric acid solution. Theoretically, this supernatant contained organic matter in solution. After the aluminum concentration of the supernatant was determined, a solution with the same aluminum concentration was prepared by adding aluminum sulfate to $4 \mathrm{dm}^{3}$ acid solution ( $0.05 \mathrm{M}$ sulfuric acid). The supernatants and aluminum sulfate solution were separately filtered through the NF membrane under the pressure of $0.67 \mathrm{MPa}$. To examine the effect of pressure, another series of experiments were performed under the filtration pressure of $1.47 \mathrm{MPa} .6 \mathrm{dm}^{3}$ of supernatant solutions were prepared by adding $420 \mathrm{~g}$ sludge to 0.15 and $0.25 \mathrm{M}$ sulfuric acid solutions, whose final total volumes were $7 \mathrm{dm}^{3}$.

In the above experiments, a series of solution samples were collected at regular intervals, filtered and analyzed by the atomic absorption spectrometry method (Z-5000 Hitachi Co., Japan) to determine the aluminum concentrations. A total organic carbon analyzer (Model: Tekmar Phoenix 8000) was used to determine the concentration of organic matter in each sample.

\section{RESULTS AND DISCUSSION}

\subsection{ALUMINUM REJECTION RATES OF UF AND NF MEMBRANES}

Both UF and NF membrane tests were performed to determine the preferred aluminum recovery method. The experimental results indicated that the flux through the UF membrane was higher than that through the NF membrane because the pores of the UF membrane were larger. The permeate aluminum concentration obtained using the NF membrane was $36.4 \mathrm{mg} / \mathrm{dm}^{3}$ whereas that obtained using the UF membrane was $939.3 \mathrm{mg} / \mathrm{dm}^{3}$. According to Eq. (2), the rejection rate in the NF membrane test was $96 \%$ and that in the UF membrane test was $14 \%$. This result reveals that the NF membrane effectively intercepts and concentrates multi-valence aluminum ions.

\subsection{RELATIONSHIP BETWEEN THE CONCENTRATION OF FEED AND CONCENTRATION OF CONCENTRATE}

In sludge acidification, the concentration of the dissolved aluminum varies with the acidity of the solution used. The permeate flux, cumulative volume of the permeate solution and osmotic pressure (calculated using Eq. (3)) depend on time (Figs. 1, 2). When the permeate flux was close to $1 \mathrm{dm}^{3} / \mathrm{m}^{2} \mathrm{~h}$, the osmotic pressure of the solution exceeded the operating pressure of the pump. In this stage, the change in the cumulative volume of the solution that passed through the membrane is very limited (Fig. 1, and the concentrating process is terminated. The data in Fig. 3 reveal that the final concentrations of aluminum from the three feeding solutions reached approximately $8000 \mathrm{mg} / \mathrm{dm}^{3}$. 
Therefore, independently of the initial feeding concentration, a pressure of $0.67 \mathrm{MPa}$ recovered aluminum at a concentration of close to $8000 \mathrm{mg} / \mathrm{dm}^{3}$. These results reveal that when the concentrating process is performed in pure aluminum solution, increasing the initial feed concentration does not alter the final concentration of aluminum in the concentrate.

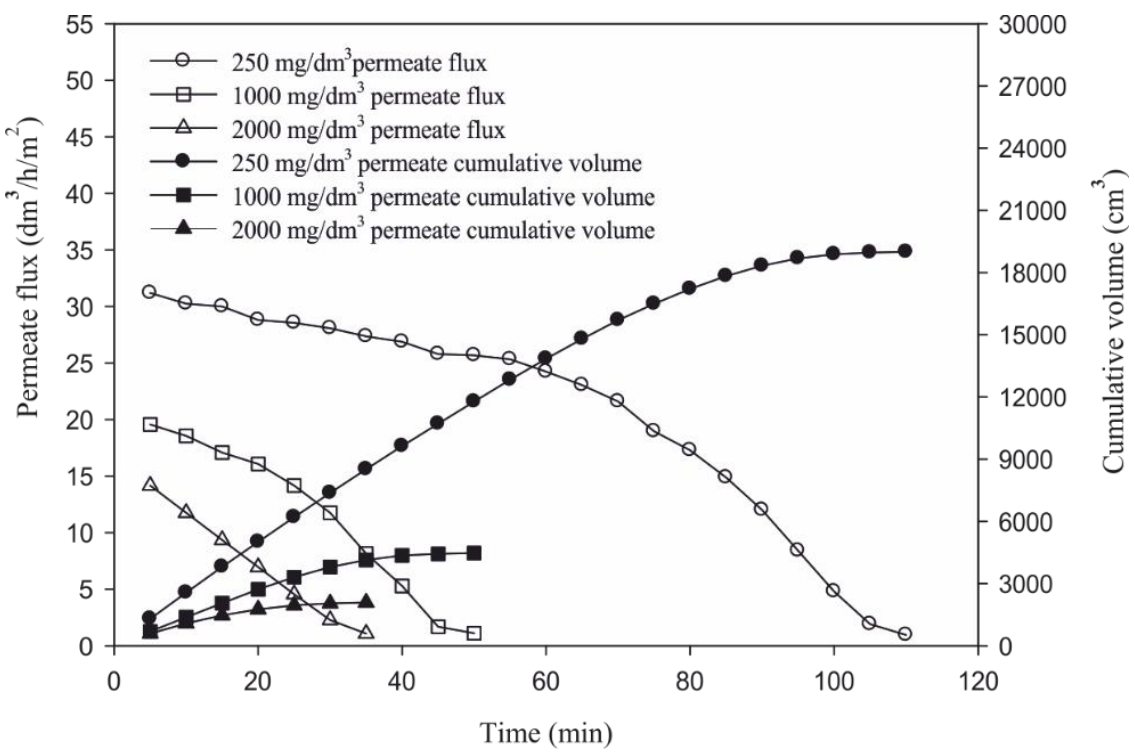

Fig. 1. Permeate flux and cumulative liquid volume in the aluminum concentration process

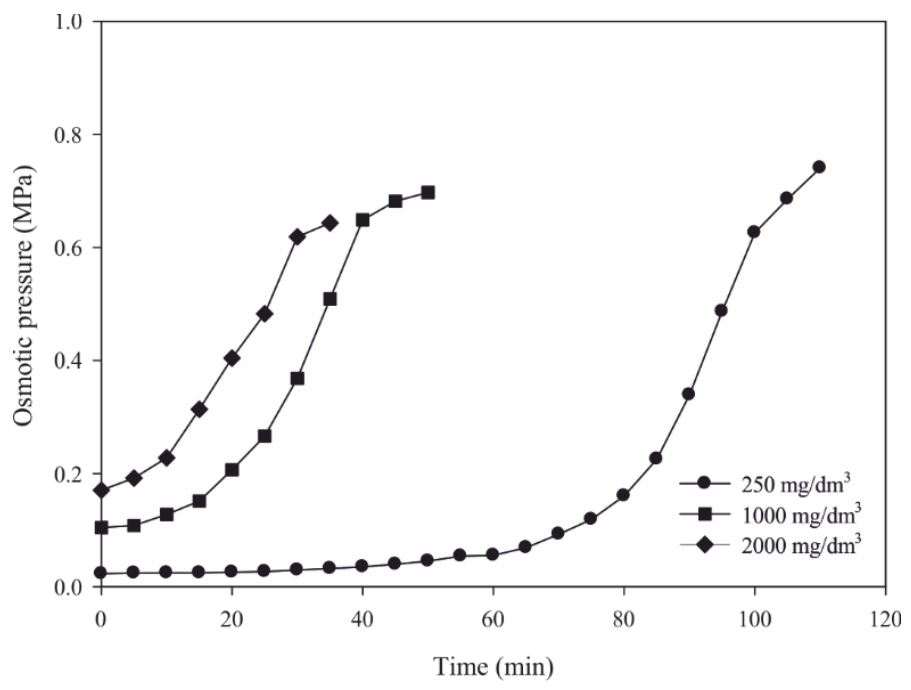

Fig. 2. Osmotic pressure in the aluminum concentration process 


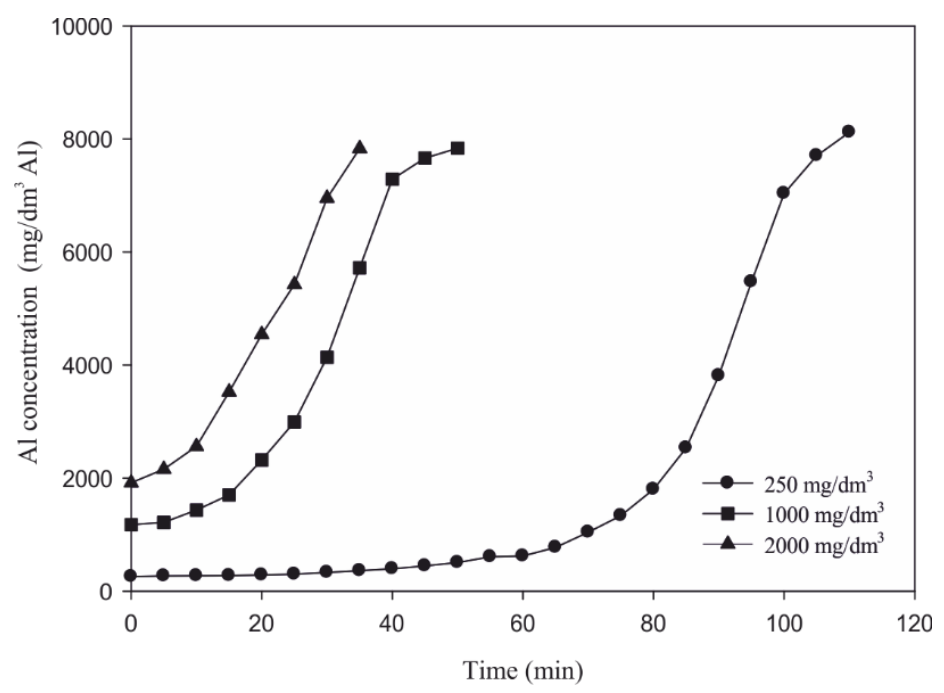

Fig. 3. Aluminum concentration in the aluminum concentration process

\subsection{EFFECT OF ORGANIC MATTER}

ON THE CONCENTRATION OF ALUMINUM IN SOLUTION OF THE CONCENTRATE

Two solutions were prepared from acidified sludge and pure aluminum sulfate. The sludge-acidified solution contained $1017 \mathrm{mg} / \mathrm{dm}^{3}$ aluminum, thus the aluminum concentration of the pure aluminum sulfate solution was also adjusted to $1017 \mathrm{mg} / \mathrm{dm}^{3}$. These two solutions were separately used in NF membrane filtration experiments.

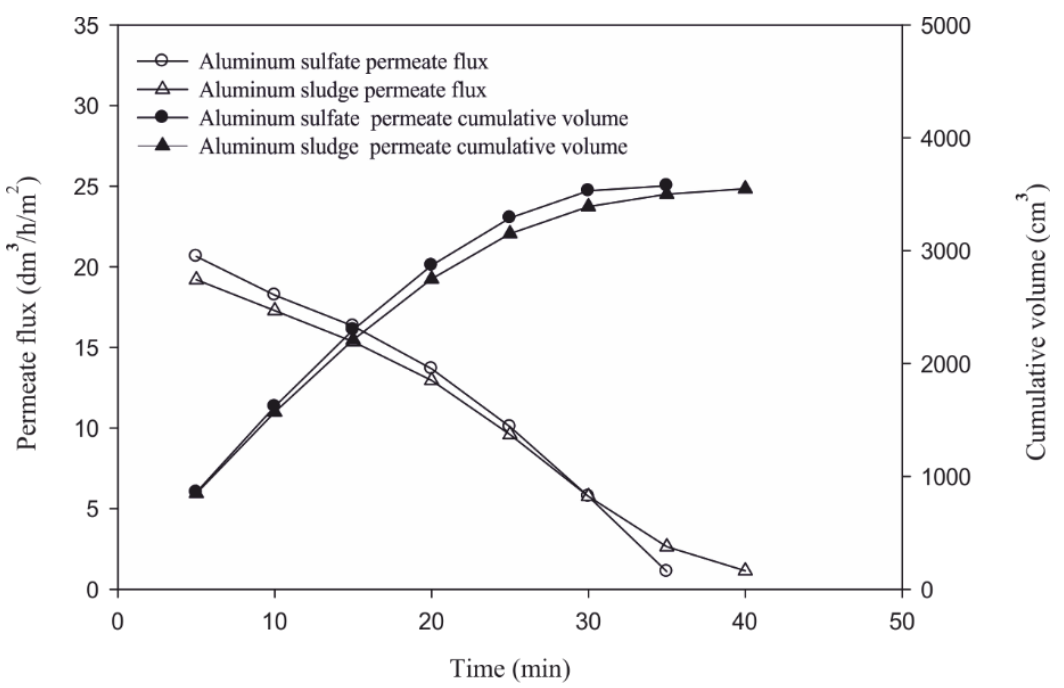

Fig. 4. Permeate flux and cumulative liquid volume in the aluminum recovery process 
Although the final cumulative volumes of permeate solution were equal, the permeate flux (membrane flux) of the aluminum sulfate solution exceeded that of the acidified sludge solution (Fig. 4). This means that organic matter in aluminum solutions may reduce the membrane flux and increase the filtration time.

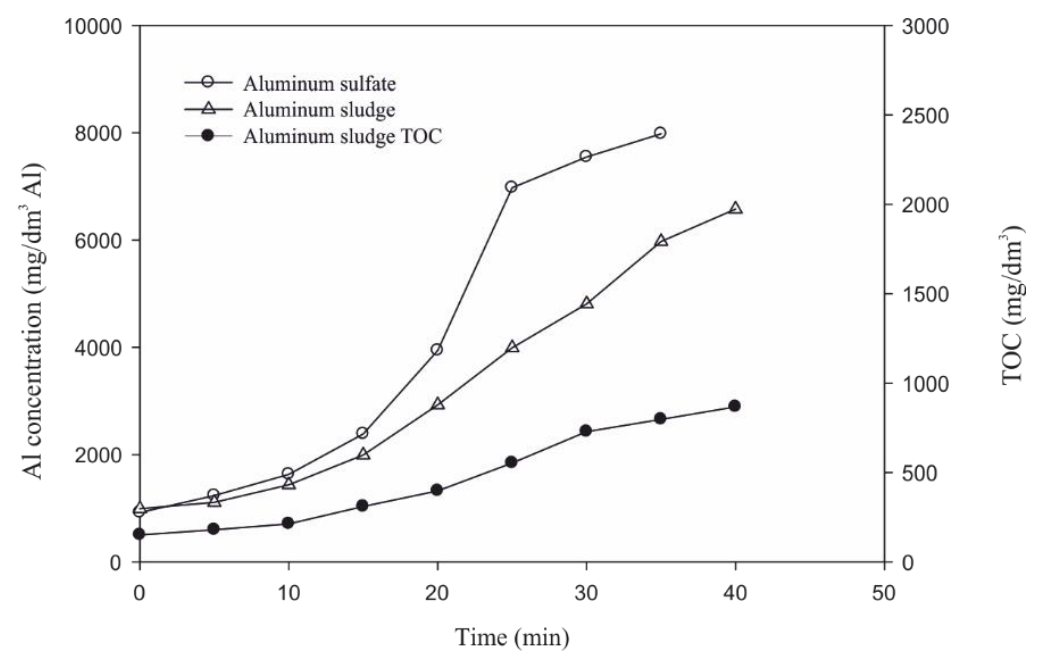

Fig. 5. Aluminum and TOC concentrations in the aluminum recovery process

The final aluminum concentration in the aluminum sulfate solution was $8037 \mathrm{mg} / \mathrm{dm}^{3}$. while its concentration in the acidified sludge solution was $6523 \mathrm{mg} / \mathrm{dm}^{3}$ (Fig. 5). Theoretically, the concentrations of aluminum in both solutions should be equal because these two solutions had the same residual volumes after filtration. However, organic matter was dissolved as the sludge was acidified.

The concentration of organic matter increased from $150.8 \mathrm{mg} / \mathrm{dm}^{3}$ to $876.8 \mathrm{mg} / \mathrm{dm}^{3}$ during filtration through the NF membrane. In the filtration process, the complexation of metal ion species with humic substances caused some of the aluminum to combine with organic matter and then be deposited on the membrane surface or in the pores of the membrane [21-23]. For this reason, the concentration of aluminum recovered from the acidified sludge solution was lower than that in the aluminum sulfate solution. In the acidification process, the dissolved organic matter may influence the efficiency of the concentration of aluminum concentrate. Therefore, the difference between the aluminum concentrations in those two solutions exceeds the difference between membrane fluxes (Figs. 4, 5). Additionally, as the filtration time increased, the higher concentration of organic matter corresponded to a larger difference between the aluminum concentrations in these two solutions. 


\subsection{EFFECT OF SLUDGE ACIDIFICATION \\ ON THE CONCENTRATION OF ALUMINUM IN CONCENTRATE SOLUTION}

High recovery of aluminum can be obtained by adding a large amount of sludge in acidic solution, but so doing causes difficulty in separating solids from the solution. Therefore, for economic reasons and convenience, the dose of sludge added to the acidic solution is not overly high. In contrast, in the sludge acidification process, adding more sulfuric acid dissolves more aluminum ions. To study the relationship between the dissolved aluminum concentration and the sulfuric acid dosage, five $60 \mathrm{~g}$ samples of sludge were separately added to $1 \mathrm{dm}^{3}$ sulfuric acid solutions of different concentration.

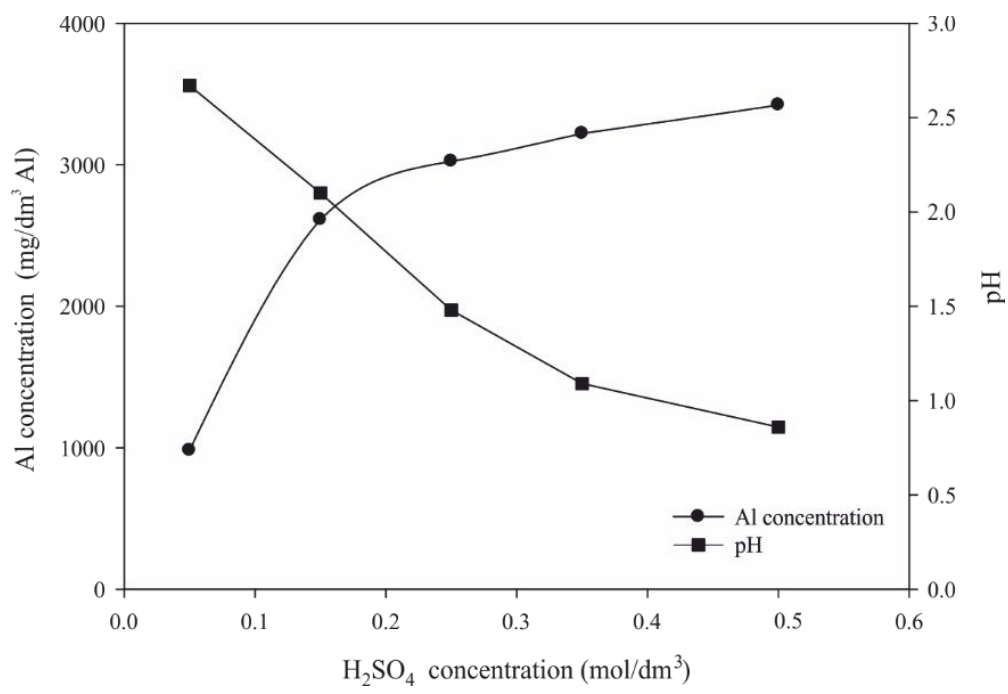

Fig. 6. Aluminum concentration and $\mathrm{pH}$ vs. sulfuric acid concentration

For the $0.05 \mathrm{M}$ sulfuric acid, the aluminum concentration was $982.1 \mathrm{mg} / \mathrm{dm}^{3}$, for $0.15 \mathrm{M}$ sulfuric acid, it was 2.66 times higher, equaling $2612 \mathrm{mg} / \mathrm{dm}^{3}$ (Fig. 6). Increasing the concentration of sulfuric acid above $0.15 \mathrm{~mol} / \mathrm{dm}^{3}$ only slightly increased the aluminum concentration. This result indicates that when the solution $\mathrm{pH}$ was adjusted to a low value, the outer layer of the sludge particles, which was solid $\mathrm{Al}(\mathrm{OH})_{3}$, reacted with $\mathrm{H}^{+}$ions, dissolving the aluminum ions. The core of the $\mathrm{Al}(\mathrm{OH})_{3}$-containing sludge gradually decreased, causing the inert diffusion layer (formed from $\mathrm{SiO}_{2}$ and $\mathrm{Al}_{2} \mathrm{O}_{3}$ in the sludge) to dominate the reaction. Even increasing the concentration of $\mathrm{H}^{+}$ions did not enable the inner solid layer of $\mathrm{Al}(\mathrm{OH})_{3}$ to dissolve easily [24]. Therefore, for economic reasons and to provide the best $\mathrm{pH}$ for use of the NF membrane which is suggested to be between 2 and 12, the minimum $\mathrm{pH}$ should not be lower than 1.5. Hence, in this work, the concentration of the sulfuric acid used in sludge acidification was $0.15 \mathrm{~mol} / \mathrm{dm}^{3}$. When the aluminum-dissolving reaction of $60 \mathrm{~g} / \mathrm{dm}^{3}$ sludge solution was 
stabilized, pH was 2.2 (Fig. 6). This acidified sludge solution was used in the following experiments so that the results could be compared with each other.

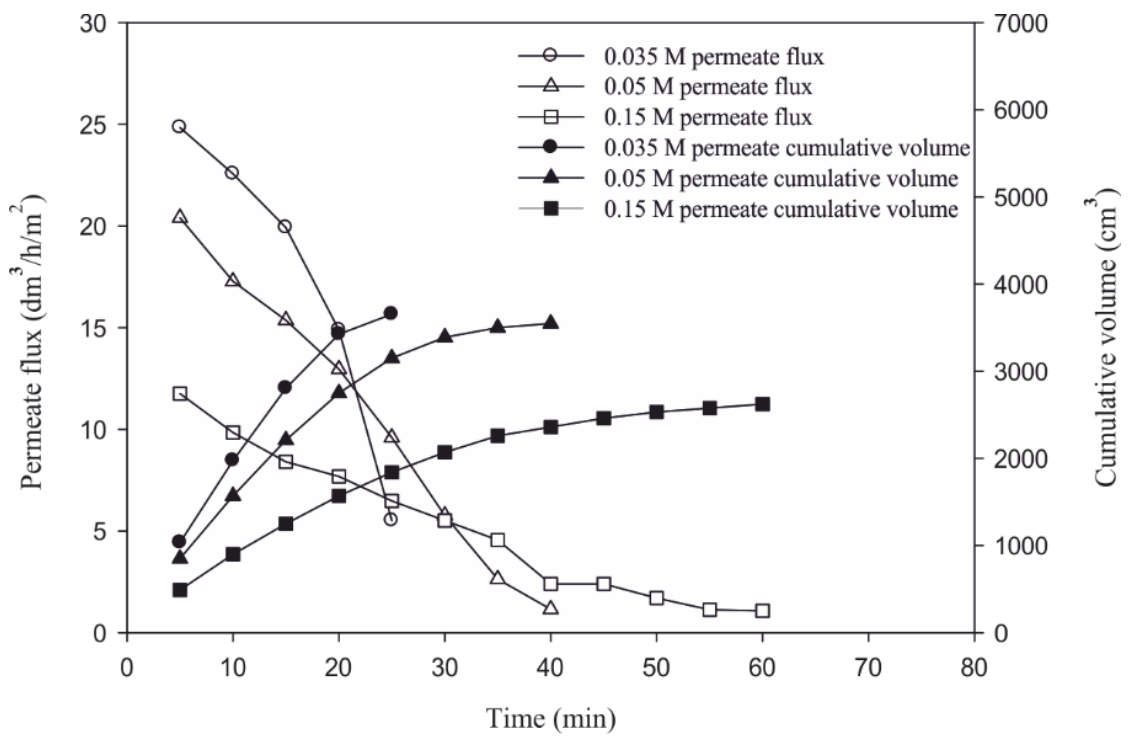

Fig. 7. Time dependences of the permeate flux and cumulative liquid volume in the filtration process (operational pressure of $0.67 \mathrm{MPa}$ )

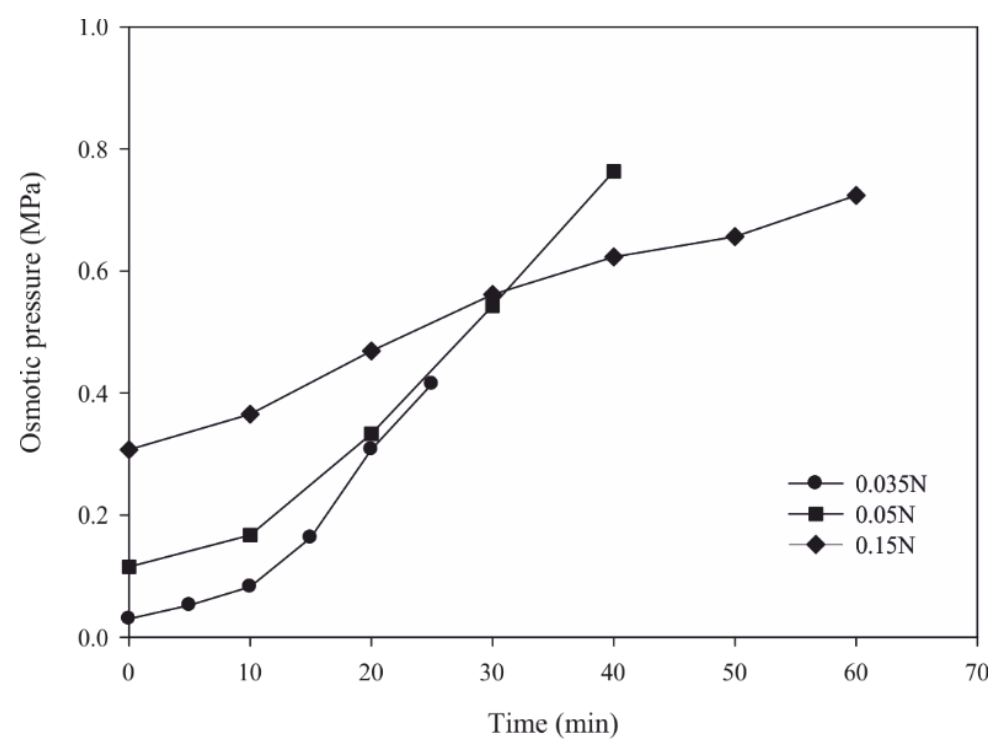

Fig. 8. Time dependence of the osmotic pressure in the filtration process (operational pressure of $0.67 \mathrm{MPa}$ ) 
Based on the experimental results, three samples of sludge were added to $5 \mathrm{dm}^{3}$ of sulfuric acid solution of the concentrations of $0.035,0.050$ and $0.150 \mathrm{~mol} / \mathrm{dm}^{3}$. After $3 \mathrm{~h}$ of mixing, the measured $\mathrm{pH}$ values were 2.9, 2.6 and 2.2, respectively. After solid -liquid separation, $4 \mathrm{dm}^{3}$ of the supernatant solution was used to examine the effect of $\mathrm{pH}$ on the filtration process under the pressure of $0.67 \mathrm{MPa}$. In $0.035 \mathrm{M}$ sulfuric acid solution, the concentrations of both organic matter and aluminum were relatively low in the initial filtration stage (Fig. 7).

In such a low-concentration solution, the osmotic pressure is low so that the membrane fluxes are relatively high. When the solution was filtered for $25 \mathrm{~min}$, the cumulative volume of the obtained permeate solution exceeded $3.6 \mathrm{dm}^{3}$. The volume of the remaining feed solution became too small to be filtered. In contrast, when the osmotic pressure exceeded the operational pressure of $0.67 \mathrm{MPa}$, the membrane fluxes of the 0.05 and $0.15 \mathrm{M}$ sulfuric acid solutions decreased below $1 \mathrm{dm}^{3} /\left(\mathrm{m}^{2} \cdot \mathrm{h}\right)$ so the cumulative volume of the permeate solution almost stopped increasing (Figs. 7, 8).

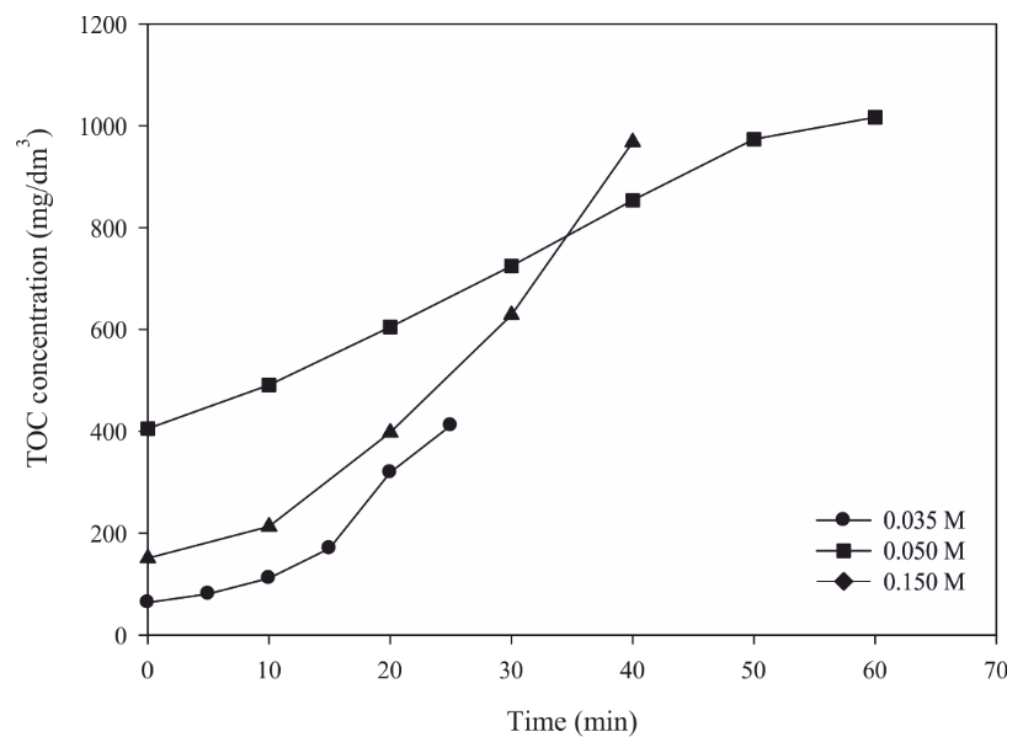

Fig. 9. Time dependence of the concentration of organic matter in the filtration process (operational pressure of $0.67 \mathrm{MPa}$ )

The data in Figs. 9 and 10 reveal that the initial concentrations of the dissolved organic matter and the aluminum increased upon increasing the concentration of sulfuric acid. Therefore, according to Fig. 7, the membrane flux of the $0.05 \mathrm{M}$ solutions was much higher than that of the $0.15 \mathrm{MN}$ solution. The data in Figure 7 also reveal that the filtrating velocity of the $0.15 \mathrm{M}$ solution exceeded that of the $0.15 \mathrm{M}$ solution and the change in the membrane flux of the $0.05 \mathrm{M}$ solution was rapid. 
The change in the permeate volume of the $0.05 \mathrm{M}$ solution was rapid, thus the changes in concentrations of both organic matter and aluminum ions were also rapid (Figs. 9, 10). Therefore, after $30 \mathrm{~min}$ of filtration, about $0.5 \mathrm{dm}^{3}$ and $2.0 \mathrm{dm}^{3}$ of the $0.05 \mathrm{M}$ and $0.15 \mathrm{M}$ solutions remained. Further filtration of the $0.05 \mathrm{M}$ solution only slightly increased the permeate volume but a large increase in the concentrations of aluminum and organic matter in the solution thus obtained. Consequently, the data in Figs. 9 and 10 indicate that the concentrations of both organic matter and aluminum ions in the $0.05 \mathrm{M}$ solutions exceeded those in the $0.15 \mathrm{M}$ solutions after $30 \mathrm{~min}$ of filtration.

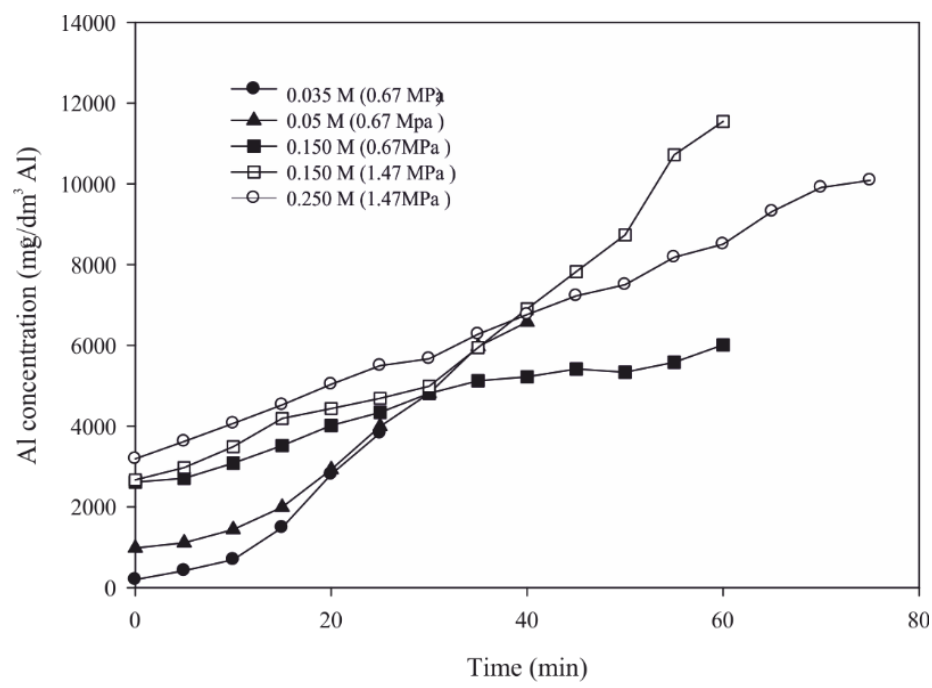

Fig. 10. Time dependence of the aluminum ion concentration in the filtration process (operational pressures 0.67 or $1.47 \mathrm{MPa}$ )

The initial aluminum concentration in the $0.05 \mathrm{M}$ solution is clearly lower than that in the $0.15 \mathrm{M}$ solution (Fig. 10). However, after $40 \mathrm{~min}$ of filtration, the aluminum concentration in the $0.05 \mathrm{M}$ solutions was $6523 \mathrm{mg} / \mathrm{dm}^{3}$, whereas concentrating the aluminum ions in the $0.15 \mathrm{M}$ solution to over $6000 \mathrm{mg} / \mathrm{dm}^{3}$ takes $60 \mathrm{~min}(0.67 \mathrm{MPa})$. The initial concentrations of organic matter and aluminum in the $0.15 \mathrm{M}$ solution exceed that in the $0.05 \mathrm{M}$ solution. Therefore, the membrane flux of $0.05 \mathrm{M}$ solution exceeds that of $0.15 \mathrm{M}$ solutions, and the filtration time of the $0.05 \mathrm{M}$ solution is shorter than that of the $0.15 \mathrm{M}$ solution. In spite of this fact, the final aluminum concentration in the $0.15 \mathrm{M}$ solution is close to that in the $0.05 \mathrm{M}$ solution but in the $0.15 \mathrm{M}$ solution the cumulative volume of the permeate solution was lower and the volume of the remaining concentrated solution - higher (Figs. 7, 10). This means that the $0.15 \mathrm{M}$ sulfuric acid solution not only has the optimal $\mathrm{pH}$ but also may yield the highest amount of aluminum in the concentrate when an NF membrane is used in the filtration process. 


\subsection{EFFECTS OF SLUDGE ACIDIFICATION ON THE CONCENTRATION OF ALUMINUM IN CONCENTRATE UNDER ELEVATED PRESSURE}

In the examination of the effect of sludge acidification on the concentration of aluminum, 0.15 and $0.25 \mathrm{M}$ solutions were used under the operational pressure of $1.47 \mathrm{MPa}$. The final concentration of aluminum ions obtained under the pressure of $1.47 \mathrm{MPa}$ was higher than that under 0.67 MPa. Increasing the operation pressure was found to increase the efficiency of concentration of aluminum. However, the data in Fig. 10 also show that the final concentration of aluminum in the $0.25 \mathrm{M}$ solution was lower than that in the $0.15 \mathrm{M}$ solution. Increasing the concentration of the sulfuric acid above $0.15 \mathrm{M}$ only slightly increased the initial concentration of dissolved aluminum but obviously increased the initial concentration of organic matter. Therefore, when an NF membrane was used to concentrate the aluminum solution, adding an excess of acid to the sludge solution did not necessarily increase the concentration of the aluminum in the concentrate solution.

\section{CONCLUSIONS}

- The NF membrane effectively concentrated aluminum. However, the organic matter from the sludge may have reduced the concentration of the recovered aluminum.

- Increasing the concentration of sulfuric acid above a certain value only gradually increased the concentration of the dissolved aluminum. However, when the NF membrane was used to concentrate the aluminum, the required dosage of the sulfuric acid could be reduced and the aluminum concentration increased.

- In the NF membrane filtration experiment, increasing the operating pressure increased the aluminum recovery rate.

- Organic matter that was dissolved during the acidification process might reduce the final concentration of aluminum in the NF membrane filtration test. Adding too much acid reduced the final concentration of aluminum.

\section{ACKNOWLEDGEMENT}

The authors acknowledge the financial support of the National Science Council, Taiwan, R.O.C. for this work (NSC-98-2221-E-239-006-MY3).

\section{REFERENCES}

[1] Evuti A.M., Lawal M., Recovery of coagulants from water works sludge. A review, Adv. Appl. Sci. Res., 2011, 2, 410.

[2] IsHIKAWA S., UEDA N., OKUMURA Y., IIDA Y., BABA K., Recovery of coagulant from water supply plant sludge and its effect on clarification, J. Mater. Cycles Waste Manage., 2007, 9, 167. 
[3] Panswad T., Chamnan P., Aluminum recovery from industrial aluminum sludge, J. Water Supply, 1992, 10, 159.

[4] MASSChelein W.J., Devleminck R., GenOt J., The feasibility of coagulant recycling by alkaline reaction of aluminum hydroxide sludge, Water Res., 1985, 19, 1363.

[5] Li C.W., Lin J.L., KANG S.F., LiAng C.L., Acidification and alkalization of textile chemical sludge: volume/solid reduction, dewaterability, and Al(III) recovery, Sep. Purif. Technol., 2005, 42, 31.

[6] Dhage S.S., Paramasivam R., Ravindar R., Andey S.P., Recovery of alum from water treatment sludge by liquid ion exchange (LIE) technique, J. Indian Wat. Works Assoc., 1985, 17, 193.

[7] Li P., SENGUPTA A.K., Selective recovery of alum from clarifier sludge using composite ion exchange membranes, Proc. 27th mid Atlantic Ind. Waste Conf., Bethlehem, PA, 1995.

[8] Prakash P., SenGupta A.K., Selective coagulant recovery from water treatment plant residuals using Donnan membrane process, Environ. Sci. Technol., 2003, 37, 4468.

[9] KU Y., LEE P.L., WANG W.Y., Removal of acidic dyestuffs in aqueous solution by nanofiltration, J. Membrane Sci., 2005, 250, 159.

[10] BowEN W.R., WeLFOOT J.S., Modeling the performance of membrane nanolfiltration critical assessment and model development, Chem. Eng. Sci., 2002, 57, 1121.

[11] Bargeman G., Vollenbroek J.M., Straatsma J., SchroËn C.G., Boom R.M., Nanofiltration of multi-component feeds. Interactions between neutral and charged components and their effect on retention, J. Membrane Sci., 2005, 247, 11.

[12] TANNINEN J., MÄNTTÄRI M., NYSTRÖM M., Nanofiltration of concentrate acidic copper sulfate solutions, Desalination, 2006, 198, 92.

[13] NySTRÖM M., TANNINEN J., MÄNTTÄRI M., Separation of metal sulfates and nitrates from their acids using nanofiltration, Membrane Technol., 2000, 117, 5.

[14] TANninEn J., Nyström M., Separation of ions in acidic conditions using NF, Desalination, 2002, 147, 295.

[15] TANNINEn J., MäNTTÄRI M., NySTRÖM M., Acid separation with nanofiltration. Effect of electrolyte strength and Donnan forces, Desalination, 2006, 199, 253.

[16] KARAKULSKI K., MORAWSKI A.W., Treatment of spent emulsion from a cable factory by an integrated UF/NF membrane system, Desalination, 2002, 149, 163.

[17] NiEWERSCH C., ABels C., Li R., WinTGENS T., Mass transport modelling to estimate the efficiency of nanofiltration application for the recovery of phosphorus from sewage sludge, Desalin. Water Treat., $2009,6,86$.

[18] ULMERT H.D., Method for treatment of sludge from waterworks and wastewater treatment plants, US Patent, US7713419 B2, May 11, 2010.

[19] Cath T.Y., Childress A.E., Elimelech M., Forward osmosis. Principles applications and recent developments, J. Membrane Sci., 2006, 281, 70.

[20] YUAN W., ZydNeY A.L., Humic acid fouling during ultrafiltration, Environ. Sci. Technol., 2000, 34, 5043.

[21] MiRA P., MARIJA K.M., Interaction of humic substances and aluminum formation of insoluble associates, Food Technol. Biotechnol., 1996, 34, 81.

[22] YuAN W., ZydNETY A.L., Humic acid fouling during microfiltration, J. Membrane Sci., 1999, 157, 1.

[23] Weng L., Temminghoff E.J., Van Riemsdijk W.H., Aluminum speciation in natural waters: measurement using Donnan membrane technique and modeling using NICA-Donnan, Water Res., 2002, $36,4215$.

[24] Cheng W.P., Fu C.H., YU R.F., Dynamics of aluminum leaching from water purification sludge, J. Hazard. Mater., 2012, 217-218, 149. 